\title{
POPULATION STRUCTURE AND EFFECTIVE SIZE OF A LIZARD POPULATION
}

\author{
Donald IV. Tinkle \\ Museum of Zoology, University of Michigan, Ann Arbor
}

Accepted July 30, 1965

\begin{abstract}
Sewall Wright, R. A. Fisher, and others have shown the influence of population size on the fluctuation in gene frequencies but have disagreed on the explanation for it. The ratio of the effective population number to the actual number is a measure of the extent to which parents make unequal contributions to succeeding generations.

For the past few years I have been studying the population ecology and dynamics of the lizard Uta stansburiana stejnegeri in western Texas. During this time data have accumulated that will allow at least a crude estimate of effective number as distinguished from simple density. Because such estimates are largely unavailable for natural populations, the results of this study are presented here.
\end{abstract}

\section{Materials and Methods}

Two two-acre study areas, located six miles south of Kermit, Winkler Co., Texas, representing parts of a continuous population were divided by numbered stakes into quadrats 20 feet on a side. The two study areas are two miles apart with no possibility of interchange between them.

Within these areas, I have experienced no difficulty in marking all resident adults and over 95 per cent of the young produced in each generation. To date, I have accumulated over 13,000 captures on more than 4,000 marked individuals. The data for the years 1961-1963 are particularly complete and have been chosen for treatment here.

An attempt was made to capture and mark every juvenile within the first week or so after hatching before there was significant movement away from the hatching site. All lizards that had reached $35 \mathrm{~mm}$. in body length prior to initial capture were excluded. The average distance moved by a $U t a$ between hatching and the time that it reaches $35 \mathrm{~mm}$. is less than 20 feet. Consequently, up to this time its parentage usually can be determined.

The hatching site of each juvenile usually lies within the home range of a male and female that can be assumed to be the parents. Because there is almost no overlap between the home ranges of the females and because the home ranges of both sexes are small, this assumption is warranted.

Each marked juvenile was then followed to maturity so that an estimate could be made of which parents produced the greatest number of surviving offspring.

For each surviving offspring produced, for which parentage could be reasonably established, the parent was given a gametic contribution of 1.0. If the position of the hatching site of a juvenile lizard made it difficult to be certain of its parentage, a fractional gametic contribution was assigned to each possible parent involved. Finally, the total gametic contribution of each parent $(k)$ was determined for each generation and the mean gametic contribution $(\bar{k})$ and the variance in $k\left(s_{k}^{2}\right)$ calculated.

I am particularly grateful to Professor James F. Crow for pointing out the fact that my technique of assigning fractional gametic contributions to parents when the exact parentage of a surviving lizard is unknown will systematically reduce the variance. He has suggested a series of equations to obtain the corrected variance. However, I found that this correction increased the variance by only 10 per cent, so that the figures for effective population 
Table 1. Calculation of variance effective number and inbreeding effective number in a lizard population based on a composite of six generations (female parents only).

Variance Effective Number

$$
N_{c}=\frac{4 N_{o}-4}{k^{2}+2}=15
$$

$=14$ using corrected variance

$N_{\mathrm{o}}=$ Average number of parents in the population $=23$

$k=$ Gametic contribution of these parents to their surviving offspring $(\bar{k}=2.4)$

$k^{2}=$ Variance in $k=3.93$

Inbreeding Effective Number

$$
N_{e}=\frac{N_{0} k-2}{k-1+\frac{k^{2}}{k}}=17
$$

$=17$ using corrected measure

size were little affected, but always in the same direction. In other words, my method slightly overestimates the effective size.

Of 481 hatchlings that survived to maturity, this study included 244. Many were eliminated that were marginal to the study area, that were first captured a considerable time after hatching, or for which parentage could not be ascertained. A total of 255 parents were studied; both these and the surviving offspring represent a composite of six generations (three in each study area).

All adult lizards in area $I$ were given $450 \mathrm{r}$ of gonadal $\mathrm{x}$-irradiation just prior to the breeding season in 1962 as part of a study of radiation effects in a natural population which will be the subject of a separate paper. Area II was used as a control.

\section{Results}

The results are shown in Table 1 in which the equations of Kimura and Crow (1963) were used as a basis for estimating the effective breeding size. The reader is referred to their paper for details of computation. Inasmuch as the sex ratio was 1 and the species apparently monogamous, only data for females are shown. Because there is little overlap in the home ranges of females, I am more certain which female produced a given offspring than which male. Moreover, it can be shown that the $\bar{k}$ of females (2.4) is about the same as that of males (2.0). In a stable population $\bar{k}$ should be 2.0 . Thus, the actual and theoretical figures are in close agreement.

The effective breeding size $\left(N_{e}\right)$ is less than the mean density (i.e., the average number of lizards per acre during the breeding season over the period of this study), but indicates that the lizards are reproducing essentially at random. In fact, the ratio of effective breeding size to actual is 0.65 for a composite of the six generations ( 0.61 using corrected variance).

The inbreeding effective number was also calculated (Table 1) and was even closer to the average density $\left(N_{o}\right)$ with a ratio of 0.74 between the two.

\section{Discussion}

I have shown that Uta stansburiana is essentially an annual species with less than 10 per cent of the adults of one generation surviving until the next, so there is little overlapping of generations. We have also suggested previously (Tinkle et al., 1962) that utas are essentially monogamous. Additional data since that time strongly support this idea. Irwin (1965) has followed daily the activity of three selected pairs of $U t a$ in an area in which there is considerable overlap of their home ranges during the breeding season. The probable mating pairs, assuming monogamy, were predicted on the basis of the position of the female home ranges relative to those of the males. Each pair was followed for several weeks and the number of courtships and copulations of the six lizards scored. Eighteen of 23 courtships were with the predicted mate, as were all three observed copulations. In addition, seven other copulations involving other pairs of utas observed by me or my students over the past two years were all between predicted mates.

The pattern of variation in effective breeding size and in mean gametic contribution accords nicely with ecological theory (Table 2). In 1961, $N_{e}$ and $N_{o}$ 
TABLE 2. Variation in various population parameters of Uta stansburiana over a period of three generations on two study areas. Roman numerals designate study area concerned. The means are based upon combined data for both study areas for all three years and cannot be determined by simply adding the figures in the columns.

\begin{tabular}{|c|c|c|c|c|c|c|c|c|c|}
\hline \multirow[b]{2}{*}{ I } & \multicolumn{2}{|c|}{$\begin{array}{l}\text { Actual no. } \\
\text { resident adults } \\
\text { in area }\left(N_{0}\right)\end{array}$} & \multicolumn{2}{|c|}{$\begin{array}{c}\text { No. adults } \\
\text { making known } \\
\text { gametic contrib. }\end{array}$} & \multirow[t]{2}{*}{$\begin{array}{c}\bar{k} \\
\text { of } \\
\text { females }\end{array}$} & \multirow[t]{2}{*}{$\begin{array}{c}k^{2} \\
\text { of } \\
\text { females }\end{array}$} & \multirow[t]{2}{*}{$\begin{array}{c}\bar{k} \\
\text { of } \\
\text { males }\end{array}$} & \multirow[t]{2}{*}{$\begin{array}{c}N_{e} \\
\text { of } \\
\text { females }\end{array}$} & \multirow[t]{2}{*}{$\begin{array}{c}\text { Ratio } \\
N_{0} / N_{0}\end{array}$} \\
\hline & $\jmath$ & q & $f$ & 우 & & & & & \\
\hline 1961 & 19 & 23 & 18 & 16 & 2.9 & 2.8 & 2.5 & 18 & 0.78 \\
\hline 1962 & 21 & 20 & 18 & 15 & 1.0 & 0.1 & 1.0 & 36 & 1.80 \\
\hline 1963 & 11 & 14 & 13 & 10 & 3.4 & 4.3 & 3.7 & 8 & 0.57 \\
\hline \multicolumn{10}{|l|}{ II } \\
\hline 1961 & 25 & 36 & 24 & 22 & 1.6 & 1.1 & 1.4 & 45 & 1.25 \\
\hline 1962 & 21 & 22 & 27 & 19 & 1.6 & 0.9 & 1.4 & 29 & 1.32 \\
\hline 1963 & 18 & 25 & 14 & 16 & 4.7 & 6.1 & 5.6 & 12 & 0.48 \\
\hline Means & 19 & 23 & 19 & 16 & 2.4 & 3.93 & 2.0 & 15 & 0.65 \\
\hline
\end{tabular}

were near 1.0 on both study areas, although the differences between the two areas is barely significant $(P=0.01)$. In 1962 , all adults on area $I$ were given $450 \mathrm{r}$ of gonadal irradiation just prior to the breeding season. As a result, the number of offspring produced decreased and the mortality of young increased compared with previous years, and compared with area II which was not irradiated. This explains the high $N_{e}$ obtained in area $\mathrm{I}$ in 1962 and the greatly reduced $\bar{k}$, a parameter that was unchanged in area II in the two years.

Because of low lizard productivity and high mortality of juveniles in area $I$ in 1962 , the 1963 adult population in that area was low compared with 1962 . Such was not the case in area II where adult density remained the same in the two years. The winter of 1963-1964 was extremely mild. Our data on lizards collected during the winter showed no mortality attributable to winter kill, whereas in previous years the winter kill averaged one-third of all animals. On this basis we were able to predict a very high adult density in 1964 which did materialize in both areas. The high $\vec{k}$ reflects the unusually high survival of young produced in 1963. The per cent survival of 28 per cent in area $I$ and 24 per cent in area II is higher than any previous year and considerably higher than the mean of 18 per cent.
The differences in $s_{k}{ }^{2}$ for females between the two study areas in 1963 are not significantly different from each other $(P>0.15)$, but both are significantly different from the previous year.

The ratio of $N_{e} / N_{o}$ fell to near 0.5 in both areas in 1963 and this is difficult to explain. The differences between 1962 and 1963 in $\vec{k}$ are highly significant for both areas ( $P$ approximately 0.001 ). Because this sharp change occurred following a winter in which the survival of young was much greater, the presumed increased intraspecific competition among these young may have placed certain offspring in favorable locations at a selective advantage. In short, the offspring of certain females were favored when the intensity of selection was increased due to high population density. Thus, the decreased effective breeding size may be a manifestation of increased selection pressure.

Although the difference in the ratio of $N_{e} / N_{o}$ between the two areas is apparently not significant, it is nevertheless in the right direction. Area I in 1963 was in the process of recovering from a depleted density due to irradiation. The number of offspring produced there (318) was higher than the previous year when irradiation was administered, but still lower than in 1961 (455). In area II on the other hand, 498 young were produced, a greater num- 
ber than the previous year. Therefore, by the reasoning above, the effective breeding size in area II should have been less than in area $I$ because of greater intraspecific competition among the young, and this was the case.

It seems likely that the extremely high population density of adults in both areas in the 1964 breeding season will have an adverse influence on natality. If this is the case, as the data so far collected indicate, we can predict that the ratio of $N_{e} / N_{o}$ will rise again toward 1.0, or toward random numbers of progeny.

We have further demonstrated (unpublished data) that there is little movement by $U t a$ during their lifetime. Because there is nearly an annual population turnover, there is little intraspecific competition between the adults of one generation and their surviving offspring. Therefore, dispersive movements away from the area of hatching may be of less survival value in this species than in one with broadly overlapping generations. The average distance moved from the hatching site by a young lizard is only 18.2 feet until sexual maturity is attained (559 records).

With such a low degree of movement there may be a selective advantage for random mating, which we have demonstrated is characteristic of this population. If this is the case, the monogamous mating system, apparently unique to Uta stansburiana among lizard species studied, would be important. Such a system would allow greater outcrossing than the more usual polygamous system by involving the gametic contribution of more males and thus mitigate the effects of inbreeding in reducing genotypic variability.

The only previously published study of lizards that is similar to this one is that of Kerster (1964) based upon data collected by Blair (1960) on the lizard Sceloporus olivaceus. This species, like Uta stansburiana, is an iguanid, but is several times larger than Uta, has an enormously larger home range, and is polygamous. Kerster estimated the genetically effective neighborhood size in Sceloporus at between 225 and 270 individuals, which would be higher than that in $U t a$ although there is no simple means of directly comparing the effective breeding size and the effective neighborhood size. However, the quite limited movements of Uta (Tinkle et al., 1962) compared with Sceloporus olivaceus (Blair, 1960) make obvious a considerable difference in the neighborhood size of the two species. The work of Kerster complements that on the Uta in showing that the polygamous mating system of Sceloporus is related to large home ranges, large effective breeding size, and considerable movement of juveniles away from their hatching site and away from their home range position as juveniles.

\section{SUMMARY}

Hatchlings of known parentage of the lizard Uta stansburiana were marked on two study areas in Texas. These young lizards were followed until they became reproductive adults to obtain an estimate of the number of adult lizards that produced most of the surviving offspring. This effective breeding number of adults was generally similar to the density in the study areas. However, the effective size was high in one of the populations subjected to acute $x$-irradiation at the onset of the reproductive season and low during periods of increased density. Explanations of these results are suggested in terms of natural selection. The apparently monogamous breeding structure of this lizard is interpreted as a mechanism for reducing inbreeding.

\section{ACKNOWLEDGMENTS}

The work reported here was carried out with support from the National Science Foundation (G-15608) and the U. S. Atomic Energy Commission (AT-40-12673). I am indebted to Prof. Th. Dobzhansky, Rockefeller Institute, to Dr. James F. Crow, University of Wisconsin, to Prof. E. B. Ford, Oxford University, and to Dr. Archie C. Allen of Texas Tech- 
nological College for reading this manuscript; any errors, however, are mine.

\section{Literature Cited}

BLAIR, W. F. 1960. The rusty lizard, a population study. Univ. Texas Press, Austin, $185 \mathrm{pp}$. IRwiN, L. N. 1965. Diel activity and social interaction in the lizard, Uta stansburiana stejnegeri. Copeia, 1965(1): 99-101.
KERSTER, W. 1964. Neighborhood size in the rusty lizard, Sceloporus olivaceus. Evolution, 18: $445-457$.

Kimura, M., and J. F. Crow. 1963. The measurement of effective population number. Evolution, 17: 279-288.

Tinkle, D. W., D. McGregor, and S. Dana. 1962. Home range ecology of Uta stansburiana stejnegeri. Ecology, 43: 223-229. 